\title{
ARTE RUPESTRE E EDUCAÇÃO ETNICORRACIAL: UMA EXPERIÊNCIA PEDAGÓGICA COM BASE EM BELL HOOKS NO CURSO DE PEDAGOGIA DA UNEB-IX (BARREIRAS/BA)
}

\author{
Rafael Petry Trapp \\ Universidade do Estado da Bahia (UNEB), Barreiras, Bahia, Brasil \\ Poliana Silva dos Santos \\ Universidade do Estado da Bahia (UNEB), Barreiras, Bahia, Brasil
}

\begin{abstract}
Resumo: $O$ presente texto constitui-se no relato de uma experiência teóricoeducativa realizada com estudantes da disciplina História e Cultura Afro-Brasileira e Indígena do curso de Pedagogia da Universidade do Estado da Bahia (UNEB), em Barreiras, em 2019. Motivados por debates acadêmicos da obra teórica de bell hooks, fizemos um trabalho de campo no final do semestre (em setembro) para um sítio arqueológico localizado na Serra do Mimo, a cerca de um quilômetro de distância do próprio campus da UNEB, a fim de problematizar a presença/ausência do indígena no imaginário histórico-social da região. A combinação entre a sala de aula e a atividade de campo resultou em reflexões sobre a história indígena em Barreiras, e na conscientização acerca do racismo como um processo social estruturante da construção do olhar dos sujeitos sobre a formação histórica da região Oeste da Bahia. ${ }^{1}$
\end{abstract}

Palavras-chave: Educação Etnicorracial. Arte Rupestre. Descolonização. bell hooks.

\section{INTRODUÇÃO}

O presente texto documenta um relato de experiência pedagógica realizada com alunos de turmas (vespertino e noturno) da disciplina História e Cultura AfroBrasileira e Indígena do curso de Pedagogia da Universidade do Estado da Bahia (UNEB) Campus IX, em Barreiras, região Oeste da Bahia, no segundo semestre de 2019.

A primeira delas se refere ao estudo sistemático do livro da educadora afroamericana bell hooks Ensinando a Transgredir (2017), levado a cabo ao longo da referida disciplina. Em um exercício crítico de leitura dirigida, discutimos e aprendemos noções elementares do debate contemporâneo das relações etnicorraciais acerca da construção de perspectivas antirracistas e descoloniais na educação no Brasil, analisando os conceitos de educação como transgressão e prática da liberdade e a construção sóciohistórica das práticas e saberes pedagógicos.

A partir desses debates na universidade, fizemos um trabalho de campo no final do semestre letivo (em 26 de setembro de 2019) para um sítio arqueológico de arte rupestre localizado na Serra do Mimo, na área urbana de Barreiras, a cerca de um quilômetro do campus da UNEB (no alto da serra), com o objetivo de problematizar a 
dinâmica da presença/ausência do indígena no imaginário social da região, observado principalmente da perspectiva dos discentes do curso de Pedagogia.

A visita ao local, de existência ignorada pela maior parte dos estudantes, foi um momento de reflexão sobre a história indígena pré-colonial de Barreiras, e de conscientização do racismo como um conjunto estruturado de ideias (ALMEIDA, 2019) constituintes do olhar dos sujeitos sobre a formação histórico-social do Oeste baiano.

Este trabalho apresenta uma descrição e análise dessa experiência de trabalho de campo à luz de alguns conceitos de bell hooks mobilizados durante a vivência acadêmica em sala. Quais possíveis significados a obra dessa autora pode adquirir para pensar a estrutura racial das mentalidades sociais nesta região da Bahia? Como seu pensamento pode concorrer para a transformação do olhar do aluno de Pedagogia diante do processo de descolonização de saberes educativos?

Além deste objetivo, queremos também esboçar proposições teóricas para pensar determinadas interrelações entre arte rupestre pré-colonial e intervenções gráficas contemporâneas diversas (rabiscos, declarações de amor, frases bíblicas), uma realidade observável na Serra do Mimo, lugar em que as pinturas rupestres convivem lado a lado com os referidos grafismos, cuja existência significa, em certa medida, sua destruição.

Temos como hipótese que a busca de compreensão sobre as intencionalidades antropológicas dessas intervenções gráficas contemporâneas pode auxiliar professores a realizar atividades pedagógicas de campo similares à que fizemos, mas com estudantes da educação básica. Conscientes da necessidade de preservação de um registro humano que também ajuda a explicar sua existência no mundo, eles podem ser os atores multiplicadores da conservação desse - e de outros - patrimônio histórico e cultural.

Neste texto, utilizamos fotografias tiradas na atividade na Serra e incorporamos relatos de campo dos alunos e excertos de uma prova escrita feita pelos mesmos durante o semestre de 2019.2, ocasião em que lhes foi solicitada opinião sobre a obra de bell hooks. As identidades, por questões éticas, são aqui tratadas por nomes fictícios.

\section{LENDO BELL HOOKS}

A ativista, pensadora, teórica feminista e educadora afro-americana bell hooks nasceu Gloria Watkins, em Hopkinsville, Kentucky, em 1952. Seu codinome, grafado em minúsculas para desafiar convenções linguísticas e ressaltar o conteúdo de sua escrita antes que sua personalidade, provém de sua avó materna, Bell Blair Hooks.

Esta escritora lecionou no ensino básico (elementary e high school) e em algumas das mais conhecidas universidades norte-americanas, como a Universidade Yale e o City College, e tem produzido uma obra influente nas Ciências Humanas nas últimas décadas, ao conjugar o olhar interseccional de raça, classe e gênero à compreensão crítica dos processos pedagógicos e da reprodução da dominação e das desigualdades sociais nas práticas e sistemas educativos, entre outros temas. Fortemente influenciada pelo feminismo negro e pelo pensamento do educador Paulo Freire, hooks é uma intelectual conhecida no Brasil e vem ganhando recentes leituras de suas obras e numerosas edições de seus livros por editoras brasileiras. 
TRAPPY, R. P., SANTOS, P. S. dos.

A obra que nos absorveu foi Ensinando a transgredir: educação como prática da liberdade, publicada em 1994 nos Estados Unidos e em 2013 no Brasil. Esse foi o livro escolhido para ser lido na disciplina de História e Cultura Afro-Brasileira e Indígena da UNEB por ao menos duas razões. Uma delas de ordem mais geral: sou um professor branco ensinando conteúdos de educação etnicorracial. Tal fato pessoal/social impunha, frente à minha própria consciência e em coerência com minha formação acadêmica, a utilização de intelectuais negros na disciplina. De modo mais específico e prático, precisávamos de um texto-base que fosse consistente e aprofundado teoricamente, mas também dono de uma leitura envolvente para os discentes.

bell hooks foi uma escolha acertada. Seu texto fluido, bem escrito, compreensível e empático - e freireano - cativou intelectualmente os alunos, na maioria alunas, e em grande medida negras ou não brancas, de localidades da zona rural, que se identificaram com a trajetória da autora, uma mulher negra de um pequeno município do interior do Sul dos Estados Unidos e que sonhava em ser professora. Nomeada simplesmente "Lendo bell hooks", a atividade consistiu primariamente na apresentação de seminários em grupo dos 14 capítulos da obra. Nesse momento, os principais conceitos da obra deveriam ser discutidos e instrumentalizados para pensar a (re)educação das relações étnicorraciais no Brasil. Mas, em linhas gerais, Ensinando a transgredircoloca quais questões?

O livro, que a autora define como um conjunto de ensaios de "intervenção" e de crítica construtiva, narra inicialmente episódios de sua vida e de suas vivências nas escolas negras (Black schools) do Sul dos Estados Unidos, especialmente no Kentucky, onde havia leis de segregação racial no sistema público de ensino até meados dos anos 1950. Ou seja, espaços formais de educação para brancos e para negros, separadamente. Em um contexto de confinamento e limitações sociais impostas por essa radical e violenta ordem racial, poucas opções se descortinavam para o futuro profissional de mulheres negras da classe trabalhadora como bell hooks, que tinham, via de regra, três opções: "Podíamos casar, podíamos trabalhar como empregadas e podíamos nos tornar professoras de escola" (hooks, 2017, p. 10).

Apesar desse universo restrito de possibilidades, hooks sublinha que as escolas exclusivas para negros foram um território do "aprendizado como revolução" (2017, p. 10), pois nesses ambientes a educação adquiria um sentido sensivelmente político, frente à opressão que atingia os alunos, os professores e as comunidades a que pertenciam. $O$ aprendizado era ansiado e a educação encarada como gesto contrahegemônico, parte de uma estratégia de resistência à imposição dos papeis sociais que o sistema racial procurava conferir e efetivamente impingia aos sujeitos marcados pela negritude e pelo desvio às normas sociopolíticas da supremacia branca. A escola negra, no entanto, era o ambiente no qual se podia contornar a noção de papeis sociais afixados pela condição racial e se "reinventar através das ideias" (hooks, 2017, p. 11).

Esse lugar social, cultural e político afro-americano em que hooks se formou seria desmantelado com o fim das escolas negras separadas, em 1955, quando a Suprema Corte dos Estados Unidos declarou inconstitucional a segregação racial nas escolas. Integrando-se às escolas brancas, o desejo de aprender dos alunos negros passou a ser encarado como ameaça à autoridade branca. A educação perderia, assim, para a criança negra, sua dimensão de "prática da liberdade, transformando-se em instrumento para reforçar uma nova estrutura de dominação" (hooks, 2017, p. 12). 
Ao entrar no curso de graduação em Letras em Stanford (uma universidade branca), a autora se animou com a possibilidade de se tornar uma professora e intelectual negra insurgente, mas se deparou com uma tediosa e contraproducente "educação bancária", conceito de Freire (1972) que designa a situação educativa na qual o professor deposita o conhecimento em um aluno desprovido de experiência intelectual. Em reação a esse quadro, hooks imaginava "modos pelos quais o ensino e a experiência de aprendizado poderiam ser diferentes" (2017, p. 15).

Na graduação, ela, que já estava engajada no pensamento feminista, descobriu a pedagogia crítica de Freire, "alguém que entendia que o aprendizado podia ser libertador" (hooks, 2017, p. 15). Além do brasileiro, suas fontes maiores de inspiração intelectual e política foram as professoras negras de sua escola de ensino fundamental e o pensamento feminista sobre a pedagogia radical. Diante da realidade da sala de aula em seu primeiro emprego como docente no ensino superior na Universidade do Sul da Califórnia, em 1976, hooks passou a elaborar caminhos pedagógicos que colocassem em movimento o entusiasmo na educação superior como um esforço coletivo no sentido da criação de uma "comunidade de aprendizado".

Segundo a autora: "Na comunidade da sala de aula, nossa capacidade de gerar entusiasmo é profundamente afetada pelo nosso interesse uns pelos outros, por ouvir a voz uns dos outros, por reconhecer a presença uns dos outros" (hooks, 2017, p. 17). O reconhecimento do outro significando o olhar para a diferença, codificada socialmente em termos raciais, de classe ou de gênero, emerge em sua análise como a rocha angular do aprendizado - e, por conseguinte, do ensino - organizado em uma comunidade colaborativa e complexa. Seria nessa oportunidade teórica da relação de ensino/aprendizagem que a transposição das fronteiras (culturais, pedagógicas, epistêmicas) poderia se processar, questionando-se "as parcialidades que reforçam os sistemas de dominação e ao mesmo tempo [proporcionando] novas maneiras de dar aula a grupos diversificados de alunos" (hooks, 2017, p. 20).

Ensinando a transgredir encontrou eco nas experiências e expectativas dos alunos de Pedagogia da UNEB. Para a discente Maria Dias, o livro trouxe "temas que mexem com a nossa realidade que se baseia no que algumas pessoas passam no seu dia a dia como a questão de raça que e vista com um olhar preconceituoso, sendo somente a etnia branca aceita [...]" e que promovem "um entendimento com mais criticidade" da dominação social. Matheus de Jesus, por sua vez, produziu uma reflexão relacionada à raça e transgeneridade: "O livro me mostrou que a minha história pode ajudar outras pessoas trans ou pelo menos conscientizar para que deixem de ser tão preconceituosas e intolerantes para com as pessoas trans que assim como os negros são tratadas como marginais [...]". Segundo o estudante, "para mudar esse quadro é preciso começar com a escola base, de baixo pra cima e assim gradativamente vamos conseguindo garantir o respeito e a visibilidade de que tanto precisamos".

Foi a partir de bell hooks e sua perspectiva de um "movimento contra as fronteiras e para além delas" (2017, p. 24), através da construção de ideias e práticas educativas e pedagógicas alicerçadas não apenas na mudança de mentalidade - estágio inicial da descolonização -, mas vinculadas a uma práxis educativa concreta por uma 
TRAPPY, R. P., SANTOS, P. S. dos.

efetiva "mudança de atitudes" (hooks, 2017, p. 68) que propusemos o trabalho de campo para o sítio arqueológico, atividade descrita e analisada na seção seguinte.

\section{NO SÍTIO ARQUEOLÓGICO DA SERRA DO MIMO}

O sítio arqueológico da Serra do Mimo se localiza no noroeste da serra homônima, na área leste da cidade de Barreiras, logo atrás e acima do Campus IX da UNEB. Uma caminhada de aproximadamente 30 minutos nos conduziu, no dia 26 de setembro de 2019, para o monumento natural que abriga, em meio ao cerrado característico do planalto ocidental baiano, as pinturas e inscrições rupestres. ${ }^{3}$ No grupo de 17 pessoas havia 10 alunos de Pedagogia, que tinham cursado História e Cultura Afro-brasileira e Indígena.

Uma das razões da atividade foi atender as exigências da Lei 11.645, de 2008, que alterou a Lei 10.639 e incluiu a obrigatoriedade da história e cultura indígenas nos currículos da rede oficial de ensino. Como falamos relativamente pouco sobre a questão indígena no curso, propus a atividade. O objetivo geral foi conversar sobre a presença de uma população tradicionalmente ausente nas narrativas da história da formação social do Oeste da Bahia, principalmente em Barreiras, um município supostamente colonizado sobre um vazio demográfico e construído pelo braço heroico predominante dos migrantes sulistas a partir dos anos 1980, principalmente gaúchos e paranaenses (BARROS, 2019). Nos paredões da Serra do Mimo, os traços materiais dessa presença negada nos discursos hegemônicos e oficiais poderiam ser vistos palpável e concretamente.

Antes de descrever esse sítio arqueológico, convém dizer em que consiste arte, inscrição ou pintura rupestre. De acordo com Carlos Etchevarne, autor de Escrito na pedra: cor, forma e movimento nos grafismos rupestres da Bahia (2007, p. 18), arte rupestre engloba "todas as variações de signos gráficos pintados ou gravados sobre suportes rochosos fixos, sejam abrigos, grutas, paredões, lajedos ou algum tipo de afloramento". Os sujeitos desses grafismos são geralmente definidos como os "grupos humanos pretéritos, vinculados a formações socioeconômicas de caçadores coletores, horticultores, agricultores ou pastores". Ainda que seja difícil ou virtualmente impossível acessar o contexto histórico, as condições sociais e os códigos simbólicos concernentes à produção cultural de povos já desaparecidos no tempo, o estudo dessa manifestação artística atesta o "processo de ocupação humana do território baiano" pré-colonial, constituindo-se a arte rupestre em marco de "memória social para as populações contemporâneas" (ETCHEVARNE, 2007, p. 11).

É segundo essa visão que analisamos a arte rupestre: não pelos seus significados, mas inserindo-a em um plano antropológico geral da constante busca do ser humano na criação de cultura e preservação da memória através de sua existência comunicativa (ISNARDIS, 1997), inscrevendo, assim, a própria historicidade de nossa humanidade em uma constituição mais plural de tempo.

Nos últimos anos, o grupo Arqueologia do Oeste da UFOB, ${ }^{4}$ coordenado pela arqueóloga Fernanda Libório Simões, vem desenvolvendo pesquisas interessantes em arqueologia na sub-região da bacia do Rio Grande. Essa autora orientou um Trabalho de Conclusão de Curso, Registros rupestres no município de Barreiras, Bahia: o sítio arqueológico Serra do Mimo (2017), de autoria de Janaína Silva Neto, em um projeto de 
iniciação científica, intitulado Caracterização arqueológica e análise preliminar do Sítio Serra do Mimo (Barreiras, Bahia), em 2018, trabalhos que trouxeram a maior parte dos dados e análises existentes sobre esse sítio.

Os pesquisadores encontraram ao menos 11 distintos painéis, sendo $10 \mathrm{em}$ forma de abrigo e 1 em gruta. As gravuras (Figuras 1 e 2) "usam a técnica de polimento, com as morfologias tridáctilos, cupules isolados, cupules em cadeias duplas, linhas concêntricas, barras paralelas e barras isoladas, trabalhadas nas temáticas biomorfos (tridáctilos) e grafismos puros". As pinturas (Figuras 3 e 4) "usam as técnicas de pincel e carimbo nas cores vermelha e amarela, com morfologias de linhas paralelas, linhas cruzadas, linhas sinuosas, círculo preenchido com linhas concêntricas e linhas concêntricas classificadas na temática grafismos puros" (LEÃO; BARBOSA; MACHADO, 2018). Simões (2019) e Silva Neto (2017) consideram que os grafismos pertencem à Tradição Nordeste e obedecem a um padrão geométrico, com motivos similares aos de sítios no Tocantins. As figuras abaixo representam as principais ocorrências de arte rupestre abordadas no trabalho de campo.

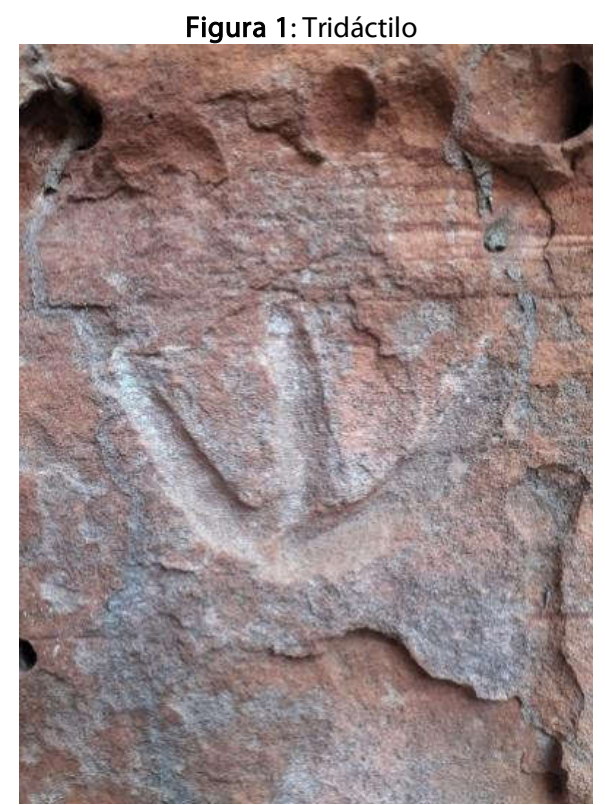

Fonte: Acervo do autor. 
TRAPPY, R. P., SANTOS, P. S. dos.

Figura 2: À esquerda, grafismos contemporâneos; cupules à direita.

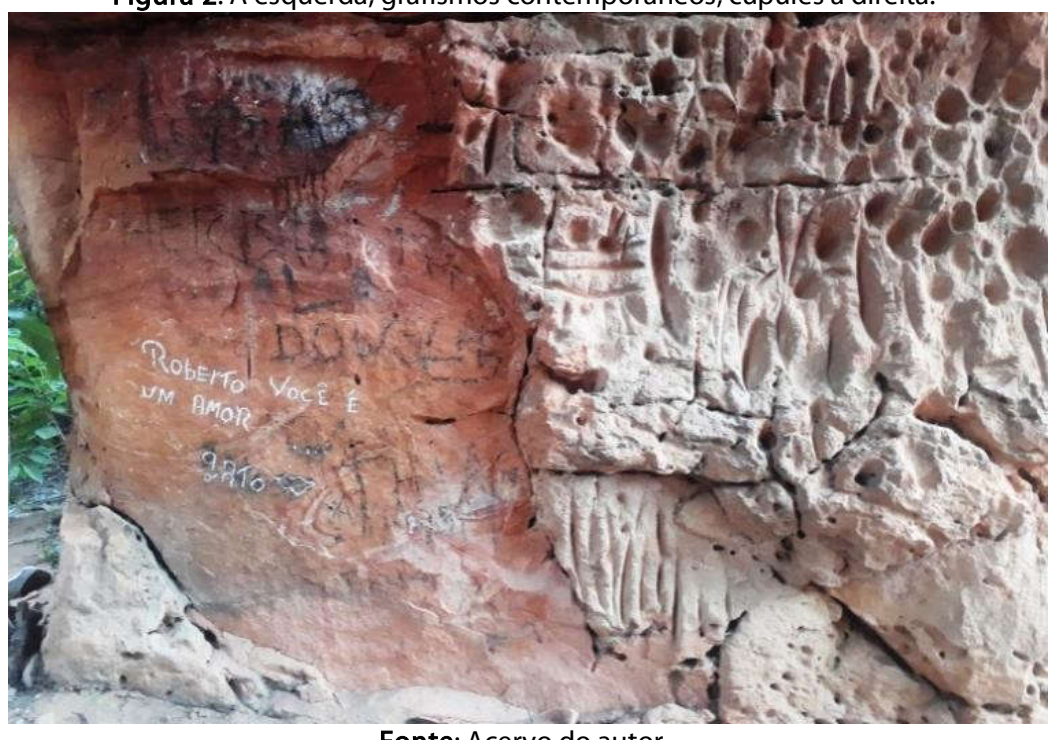

Fonte: Acervo do autor.

Na Figura 1, observa-se um tridáctilo ${ }^{5}$. Os estudantes identificaram inicialmente um pé de galinha ou de alguma ave ou pássaro, ou, ainda, uma folha. Confrontados com a possibilidade de se tratar de uma vulva, um signo de sexualidade - de acordo com informações verbais de Simões (2019) -, surpreenderam-se, em tom de galhofa, naturalmente. Procuramos ressaltar o fato de a sexualidade ser um tema constante em nossas elucubrações sobre quem somos, e, portanto, imprescindível para a discussão de como nos constituímos historicamente. Relativizamos, deste modo, a abordagem cultural da sexualidade de nossa experiência presente no plano de uma dimensão histórica mais ampla. Na Figura 2, podem ser vistas pequenas incisões circulares convexas, chamadas cupules ${ }^{6}$. Não há consenso na literatura arqueológica sobre sua função ou significado (SANTOS JÚNIOR, 2012). Note-se neste painel a existência de escritos contemporâneos diversos lado a lado com as inscrições rupestres. 
Figura 3: Círculo concêntrico.

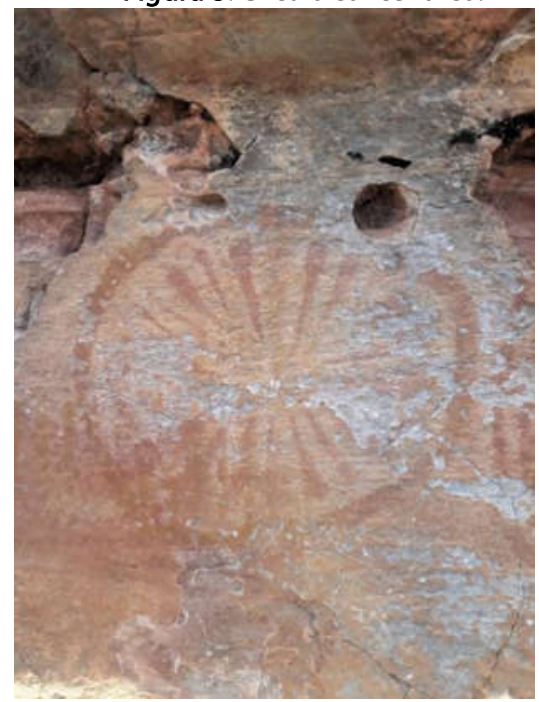

Fonte: Acervo do autor.

Figura 4: Pequena mão ao centro, feita provavelmente com técnica de gabarito.

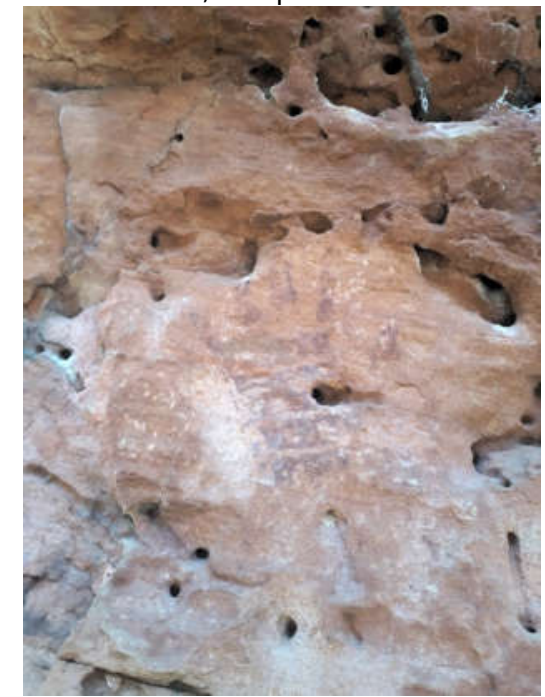

Fonte: Acervo do autor.

Na Figura 3, vê-se um círculo concêntrico, pintado com substância de fórmula química ainda não conhecida, que serviu para falarmos sobre os possíveis significados das pinturas. A tendência de nossa compreensão contemporânea foi a de identificar algum astro celeste, como um sol ou outra estrela. Todavia, reproduzimos para os alunos 
um relato que ouvíramos de um guia no sítio arqueológico do Boqueirão da Pedra Furada, na Serra da Capivara (PI), em novembro de 2018. Em dada ocasião, perante representação similar, membros de três etnias indígenas do Brasil indicaram significados diferentes para este mesmo desenho. A procura pelos sentidos precisos das gravuras rupestres configura-se, então, pouco relevante. Em contraposição, tomamos como premissa que "a variação dos temas, das maneiras de apresentá-los em épocas diferentes e as formas de aperfeiçoamento das técnicas gráficas, confugiram uma fonte de dados essencial para identificar a diversidade de códigos de apresentação e, portanto, de comunicação social" (PESSIS; GUIDON apudETCHEVARNE, 2007, p. 23).

A Figura 4, por sua vez, exibe aquela que é uma das pinturas mais significativas. No abrigo, alguém com uma mão muito pequena, quem sabe uma criança, imprimiu ali a marca desta mesma mão. Reparando com mais vagar, podem ser divisados ao menos três pequenos riscos perpendiculares ao dedo médio, feitos talvez com um graveto. $\mathrm{O}$ expediente indica, menos que um significado determinado, a existência de um pensamento abstrato, dada a intencionalidade do sujeito em comunicar algo além do formato de sua mão.

Foram esses os principais exemplares de arte rupestre em que detivemos nossa atenção para inquirir questões de história, cultura, diversidade, relativização, abstração, entre outras. Ainda que não se possa estabelecer um vínculo direto entre as populações que realizaram essa arte e os atuais povos indígenas no Brasil - cuja denominação "indígena" é, na realidade, uma construção histórica eurocêntrica, diga-se -, consideramos o sítio da Serra do Mimo, de modo indireto, no tempo e no espaço, tal como procedem em geral os especialistas nesse assunto no Brasil, como parte da história pré-colonial indígena do Oeste da Bahia.

\section{MARCAS RUPESTRES: DESAFIOS ANTROPOLÓGICOS}

No sítio da Serra do Mimo, convivendo com os resquícios da arte rupestre précolonial encontram-se dezenas de escritos, pichações e grafismos humanos modernos, que, aliados a outras intervenções antrópicas (feitas pelo ser humano) atuais, como fogueiras, vêm danificando e degradando boa parte das pinturas e inscrições rupestres. É pacífica nossa concordância com Silva Neto (2017, p. 53) acerca da necessidade de ações pelo poder público e sociedade civil no sentido da preservação de um patrimônio arqueológico, histórico e cultural primordial "para o desenvolvimento de uma identidade regional que permita ao natural da região se reconhecer na história, criar laços e sentimento de pertencimento".

Entretanto, argumentamos que um olhar antropológico compreensivo - mas, não empático - sobre a intencionalidade e os significados atribuídos aos grafismos contemporâneos pode auxiliar a posicionar a produção histórica desses gestos comunicacionais em uma superfície mais geral da experiência cultural humana no tempo. Em outras palavras, utilizar um conjunto de significados inteligíveis à nossa percepção cultural para interpelar o imaginário social relativo à arte rupestre, e, assim, constituir uma consciência educativa que efetivamente a preserve e valorize.

Em um espectro grande de possibilidades, pois a área dos painéis tem sido intensamente rabiscada e pichada, procedemos aqui a uma escolha que pensamos ilustrar bem o argumento. Na Figura 2, ao lado dos cupules e abaixo de tridáctilos, lemos 
uma expressão que qualquer um entenderia ou pensou ou até mesmo já escreveu, em algum momento da vida afetiva: "Roberto você é um amor", seguida do adjetivo "gato". O objeto do ser amoroso dessa frase devia ser um frequentador do sítio, do contrário seria difícil ou pouco provável a leitura da mensagem pelo seu destinatário. Tendo lido ou não tal declaração rupestre de amor, estamos diante de um fato social: o amor romântico. Assim como indivíduo, felicidade, infância, amor materno, o conceito de romantismo é uma invenção histórica recente (BARBOSA, 2008).

Conquanto inventado, não deixa de ser por isso significativo, funcional e/ou verdadeiro para nossa formação cultural, que o compreende e produz discursos e práticas que o põe em movimento no curso de nossas vidas. Então, assim como os povos originários ou pré-coloniais do "Oeste baiano" - outra construção recente -, nós também produzimos marcas, às vezes inseridas das maneiras as mais diversas, literalmente na pedra - caso da Serra do Mimo -, que representam o desejo de fixar os pensamentos, as ações, os sentimentos, as inquietações, as ansiedades, as memórias e as perspectivas que temos sobre a vida.

Logo, através dessa leitura das duas modalidades de "marca rupestre" constantes na Figura 2, pudemos contextualizar nossos estilos socioculturais no âmbito da diversidade de expressão de nossos sentimentos atinentes às relações humanas, em termos afetivos, sexuais, artísticos, religiosos etc., promovendo assim um reconhecimento de nossa identidade pelo confronto e pelo diálogo entre a construção do eu e a percepção do outro, embora o exercício desta alteridade só possa ser viabilizado por meio de documentais rarefeitos - os vestígios de arte rupestre.

Engendramos, como talvez concordasse bell hooks, uma atitude pedagógica que problematizou as fronteiras do que entendemos de nosso ser epistêmico e nosso devir no processo histórico. Para a estudante Daniela Oliveira, "quando somos capazes de nos colocar no lugar do outro e entender o mundo através dos valores que ele carrega, compreendemos a grandeza da cultura, da vida em sociedade, dos saberes e modos de vida independente da época em que foram produzidos". Fazendo dialogar os dois eixos temáticos e teóricos centrais da atividade, a discente Viviane Cristina enfatizou:

\footnotetext{
[...] conhecer de perto a vida dos nossos antepassados, reconstruir a história e costumes desses povos é um privilégio para poucos no mundo moderno, o sítio arqueológico da Serra do Mimo transmite o reforço e manutenção de identidades sociais, a valorização artística e manifestações culturais, a importância de reconhecer e respeitar a diversidade cultural. Como a educadora afro-americana bell hooks, em seu livro Ensinando a Transgredir traz uma reflexão do quanto é importante a transposição de fronteiras, abrir a cabeça e o coração para conhecer, pensar e repensar, criar novas visões e valorizar o sujeito como protagonista do processo ${ }^{7}$.
}

Coerentemente às colocações de Viviane Cristina, Daniela Oliveira escreve ainda que a preservação do sítio pode dar a conhecer "o processo de povoamento" do oeste baiano, "bem como os acontecimentos que resultaram no desaparecimento das 
TRAPPY, R. P., SANTOS, P. S. dos.

populações indígenas locais". Este ponto é fundamental, pois, para além do olhar compreensivo e relativizador, é preciso meditar também sobre as razões históricas e sociais pelas quais as pessoas no tempo presente se sentem à vontade ou moralmente desimpedidas para escrever, pichar ou depredar a arte rupestre - indígena.

O mais óbvio faz sentido: é provável que, ao menos nesse caso - um sítio arqueológico em área urbana, com circulação de pessoas -, os indivíduos comuns - não acadêmicos - não vejam a existência do registro artístico rupestre, ou, se porventura o façam, não visualizem sua importância enquanto patrimônio cultural do conjunto da sociedade e deles mesmos, deixando a consciência livre para rabiscar, pichar etc. Contudo, as reflexões geradas por bell hooks e pela disciplina de História e Cultura Afrobrasileira e Indígena nos fizeram ponderar se, por detrás dessa ação - que ocorre em incontáveis sítios de arte rupestre Brasil afora - não estaria o racismo, entendido como um sistema de ideias, crenças e valores que supõe a existência de grupos raciais superiores e inferiores, diferentes e desiguais entre si (TAGUIEFF, 2002).

No Brasil, é notório que as populações indígenas foram perseguidas, exploradas e oprimidas, em diferentes contextos. Rasurado historicamente, o sujeito indígena foi produzido para desaparecer física e culturalmente, um projeto que parece ter tido lugar no Oeste da Bahia ${ }^{8}$. Nossa hipótese, que certamente pode e precisa agregar dados mais consistentes para poder ser mais bem encaminhada, é a de que há uma lógica socialmente estruturada e compartilhada de produção do outro - do indígena - como inferior e, assim, invisível. Nossa visão do indígena e de outros grupos, a exemplo de negros e LGBTs, foi colonizada por noções racistas de entendimento da sociedade.

Não se trata de dizer que uma pessoa que rabiscasse um sítio de arte rupestre estaria fazendo um ato racista em sentido estrito, mas sim que na origem social dessa postura estaria uma gramática do exercício das relações raciais brasileiras, na qual o indígena é invisibilizado, idealizado e congelado como ser de um passado ao qual se aprende a atribuir pouca importância.

A educação, e aqui particularmente a educação das relações etnicorraciais, pode ser instrumento para uma mudança. Durante nossa estada na Serra do Mimo, uma das alunas, Thainá Santos, contou que ela mesma havia presenciado depredações no lugar. Seu depoimento é revelador de algumas das problemáticas levantadas:

A partir da leitura do livro de bell hooks sobre transgressão teórica e
educação libertadora, diversos estereótipos começaram a serem
quebrados, passei a vislumbrar o mundo ao meu redor mediante
uma nova ótica. Às vezes deixamos de apreciar as coisas simples da
vida, talvez as mais encantadoras e significativas, e continuamos a
reproduzir discursos prontos e inacabados sem sequer nos
interpelarmos sobre a real história daquele contexto. Ao participar
do trabalho [...] desconstruí minha visão sobre o sítio arqueológico
de pinturas rupestres da Serra do Mimo, que até então para mim era
apenas um ponto de descontração para um fim de semana, eu já
havia visitado o sítio outras vezes e inclusive, presenciei pessoas
danificando as pedras, escrevendo, fazendo fogueira, destruindo
um patrimônio histórico riquíssimo. Acredito que essas pessoas não
têm conhecimento da importância que aquele espaço tem para
nosso patrimônio histórico, assim como eu, antes de ter cursado a
disciplina. Através desse trabalho de campo, passei a conhecer a 


\begin{abstract}
imensidão de riquezas que temos em nossa região, o fato de ter havido presença indígena assim como os registros lá encontrados me deixaram encantada e ao mesmo tempo envergonhada, por de certa forma, ter contribuído, mesmo que indiretamente, para a degradação daquele lugar, por falta de conhecimento [...]. Hoje [...], sempre que surge uma oportunidade procuro conscientizar outras pessoas também.
\end{abstract}

A depredação do sítio pela falta de conhecimento são respectivamente o resultado e o processo, mas talvez seja importante investigar os fundamentos da produção social dessa ignorância. A estudante dá pistas para a desconstrução dessa mentalidade, através essencialmente do conhecimento e da educação. Em seu relato, a mediação conceitual se dá através de bell hooks, autora que nos acompanhou no decorrer da disciplina e que nos instigou a pensar em estratégias para a descolonização de nosso olhar sobre a realidade das presenças e das ausências observadas na história indígena do Oeste da Bahia.

\title{
CONCLUSÃO
}

A avaliação da disciplina e do trabalho de campo foi positiva. Ensinando a transgredir foi leitura fluida e prazerosa e ao mesmo tempo inquietante e perturbadora, posto que bell hooks não se furta em conjecturar sobre os desafios que se impõem aos educadores em termos de nossa relação com o racismo e o antirracismo na educação e também no sentido de nos fazer pensar em nosso lugar no mundo social a partir das demarcações interseccionais de raça, classe e gênero.

Assim, sublinhamos, considerando nossa experiência nessa atividade e a prática da educação etnicorracial em sala, que os educadores brancos devemos abrir espaços em nós para exercícios de alteridade para com as histórias e os lugares de fala dos sujeitos socialmente não hegemônicos (como negros e indígenas), e cultivar, em paralelo, lugares intelectuais de escuta, que possibilitem o questionamento de nossa condição sociorracial na estrutura da educação e na sua desconstrução e reconfiguração. É um posicionamento premente para se dar os passos no sentido do que hooks tem chamado em seus escritos de educação transgressora.

Ela afirma que, assim como as concepções pedagógicas e os sistemas de educação, os agentes das transgressões devem estar abertos para a mudança. $\mathrm{Na}$ contundência política de seus diagnósticos teóricos, a educadora diz que, "se realmente queremos criar uma atmosfera cultural em que os preconceitos possam ser questionados e modificados, todos os atos de cruzar fronteiras devem ser vistos como válidos e legítimos" (hooks, 2017, p. 175).

Como a experiência em sala de aula e fora dela de alguma sorte evidenciou, bell hooks provou ser uma autora potente para abordagens críticas sobre questões etnicorraciais mesmo em contextos diferentes relativamente à construção histórica das estruturas sociais, como os Estados Unidos e o Brasil. Mesmo com a consciência das diferenças históricas entre o Kentucky e o Oeste da Bahia, sua empatia humana, domínio teórico e profundidade de análise pedagógica, somadas à compreensão bem articulada 
TRAPPY, R. P., SANTOS, P. S. dos.

e inteligível sobre a produção estrutural de relações e opressões de raça, classe e gênero, calaram fundo na percepção dos estudantes da disciplina de História e Cultura AfroBrasileira e Indígena daquele segundo semestre de 2018.

Prova disso é que a escolha do tema da "III Semana de Pedagogia" do campus IX da UNEB foi, por influência dos discentes, "Pedagogias transgressoras: a educação como prática da liberdade", ocorrida em setembro de $2019^{9}$. Para a palestra de abertura do evento foi convidada a historiadora negra Alina Najara da Silva Gonçalves (UNEB - XIII), que enfatizou no texto de sua conferência que "transgredir e proporcionar uma educação como espaço de liberdades implica em desenquadrar memórias que silenciam e ocultam personagens, pessoas e lugares" (GONÇALVES, 2019, p. 11).

Diante dessa premência educativa e política, demonstramos que, ao contrário do que as narrativas da história regional apregoam, não procede a ideia do Oeste da Bahia construído em um vazio demográfico. E não é verdade também, em um contraponto ao racismo - conceito aqui entendido subjacentemente de modo institucional e estrutural (ALMEIDA, 2019) -, que os povos indígenas tenham sido e/ou sejam culturalmente inferiores, porque o indígena é no Brasil uma força viva e potente no presente ${ }^{10}$. Tal afirmação provém da constatação (Cf. Figura 4) de que a capacidade de imaginação e de pensamento abstrato não é atributo cognoscente exclusivo da branquitude.

Almejamos na atividade relatada sugerir ideias para outros atos de transgressão de fronteiras, especialmente por pedagogos, seja na Bahia ou em outros lugares do Brasil em que haja arte rupestre em contextos urbanos. Eles poderão replicar estratégias semelhantes e mesmo avançar em outros interesses, não necessariamente ligados diretamente a questões raciais (a exemplo de arte, cultura, linguagem, filosofia), como foi o nosso objetivo. A abordagem teórica desta experiência foi a de procurar apreender a produção da arte rupestre do sítio da Serra do Mimo de um ponto de vista históricocultural e relativizar nossa posição (professor e estudantes - não indígenas) antropológica referente às representações das relações humanas no tempo, concentrando atenção em temas que sensibilizem as pessoas, criando assim interesse e empatia, caso das discussões comparativas sobre os signos de sexualidade e amor romântico.

Artigo recebido em: 13/03/2021

Aprovado para publicação em: 14/10/2021

CAVE PAINTING AND ETHNIC-RACIAL EDUCATION: A PEDAGOGICAL EXPERIENCE BASED ON BELL HOOKS IN THE COURSE OF PEDAGOGY OF UNEB-IX (BARREIRAS/BA)

ABSTRACT: The text addresses a theoretical-educational experience carried out with students from the discipline of Afro-Brazilian and Indigenous History and Culture in a Pedagogy course at UNEB - Campus IX, in Barreiras (Bahia), in 2019. From the classroom debates upon bell hooks thought, we made a field work in the end of semester (September) to an archaeological site located in Serra do Mimo, about $1 \mathrm{~km}$ away from the UNEB campus, in order to problematize the presence/absence of Indigenous people in the historical and social imaginary of the region. The 
visit to this location was a moment of reflection on the Indigenous history in Barreiras, and of awareness about racism a structural social process of the construction of subjects' views on the historical formation of the West region of Bahia.

KEYWORDS: Race and Ethnic Education. Cave Art. Decolonization. bell hooks.

\section{ARTE RUPESTRE Y EDUCACIÓN ÉTNICO-RACIAL: UNA EXPERIENCIA PEDAGÓGICA CON BASE EN BELL HOOKS EN EL CURSO DE PEDAGOGÍA DE LA UNEB-IX (BARREIRAS/BA)}

RESUMEN: El presente texto es el relato de una experiencia teórico-educativa realizada con estudiantes de la disciplina de Historia y Cultura Afrobrasileña e Indígena en el curso de Pedagogía de la UNEB - Campus IX, en Barreiras (Bahía), en 2019. De los debates académicos en clase de la obra de bell hooks, realizamos un trabajo de campo al final del semestre (en septiembre) a un sitio arqueológico ubicado en la Serra do Mimo, a un kilómetro del propio campus de la UNEB, con el fin de problematizar la presencia / ausencia de los pueblos indígenas en el imaginario histórico y social de la región. La combinación del aula y la actividad de campo resultó en reflexiones sobre la historia indígena en Barreiras, y en la conciencia sobre el racismo como un proceso social estructurante de la construcción de la mirada de los sujetos sobre la formación histórica de la región Oeste de Bahía.

PALABRAS CLAVE: Educación Étnico-racial. Arte Rupestre. Descolonización. bell hooks.

\section{NOTAS}

1 - Esse artigo é resultado parcial do Projeto de Extensão "Trilhas da história: educação e descolonização de saberes no sítio arqueológico da Serra do Mimo, Barreiras/BA" (2019-2020), apoiado com bolsa pelo Programa Afirmativa da Pró-reitoria de Ações Afirmativas da UNEB.

2 - Cf. bell hooks: Olhares Negros: Raça e Representação (Ed. Elefante, São Paulo, 2019); 0 feminismo é para todo mundo: Políticas arrebatadoras (Ed. Rosa dos Tempos, São Paulo, 2018). Entre outras.

3 - O registro da trilha foi feito por meio do aplicativo Wikiloc. Cf. https://pt.wikiloc.com/trilhasmountain-bike/trilha-para-sitio-arqurologico-da-serra-do-mimo-barreiras-41729529.

4 - Cf. https://www.arqueologiadooestedabahia.com/.

5 - Para Ludmília Vaz (2005, p. 23), tridáctilos são estruturas tridimensionais "que combinam três traços partindo de um vértice", comuns na Tradição Geométrica de registro rupestre no Brasil.

6 - Segundo Santos Jr (2012, p. 9): “O conceito de cúpules entre os pesquisadores apresenta poucas variações. No campo arqueológico, uma das definições ressalta que decorre da retirada de massa rochosa pelo homem de forma de não-utilitarista, com formato predominantemente circular (que ocasionalmente aparecem de forma oval), apresentando dimensões variadas de diâmetro e podem ser encontrados em todo o mundo (Van hoek, 2003). Outra definição a menciona como depressões efetuadas na rocha, de aspecto hemiférico, de tamanhos e esboços variados, encontrados em quase todas as partes do mundo, principalmente nas proximidades de locais paleolíticos e de vilas holocênicas (Bradley, 1993; Tilley, 1994). Outro pesquisador a define 
TRAPPY, R. P., SANTOS, P. S. dos.

como petróglifos em forma de cúpulas hemisféricas [...] criados pela mão humana através de percussões diretas em suportes horizontais ou verticais, com função não utilitária (Bednarik, 2003)".

7 - Depois da atividade, a bolsista enviou a seguinte pergunta para participantes da saída de campo: "Na condição de discente de Pedagogia e tendo como base as reflexões de bell hooks sobre transgressão teórica e educação libertadora, qual sua leitura do trabalho de campo para o sítio arqueológico de pinturas rupestre da Serra do Mimo para a problematização de nosso imaginário pessoal e social diante da presença histórica indígena na região Oeste da Bahia?" Citamos aqui os depoimentos das pessoas que responderam.

8 - Cf. Fernanda L. Simões em relação a esse ponto: https://www.youtube.com/watch?v=6cpua78cONE. 9 - Cf. https://www.semanacientificauneb.com.br/.

10 - A atividade de campo foi realizada também para, no contexto da disciplina da UNEB, em 2019, dar conta de um assunto que foi na ocasião pouco abordado: a história indígena na educação etnicorracial. Contudo, reconhecemos a ausência de epistemologias indígenas brasileiras nessa disciplina e neste artigo, lacuna sobre a qual pretendemos trabalhar em produções futuras, em níveis de ensino, pesquisa e extensão.

\section{REFERÊNCIAS}

ALMEIDA, S. L. Racismo estrutural. São Paulo: Pólen, 2019. Coleção Feminismos Plurais.

BARBOSA, D. R. O império do amor romântico: diferenças culturais e sexuais em casais de noivos no Brasil e na Itália. Tese (Doutorado em Psicologia) - Departamento de Psicologia, Universidade de São Paulo, São Paulo, 2008.

BARROS, Y. B. A invenção da Metrópole da Soja: entre a modernização do Oeste da Bahia e o discurso de progresso na imprensa local (1980-1989). Trabalho de Conclusão de Curso (Graduação em História) - UFOB, Barreiras, 2019.

ETCHEVARNE, C. Escrito na Pedra: cor, forma e movimento nos grafismos rupestres da Bahia. São Paulo: Versal Editores, 2007.

FREIRE, P. Pedagogia do Oprimido. Lisboa: Edições Afrontamento, 1972.

GONÇALVES, A. N. da S. Pedagogias transgressoras: a educação como prática da liberdade. Revista do Coletivo Seconba, Barreiras, v. 3, n. 1, p. 3-12, nov. 2019.

hooks, b. Ensinando a transgredir: a educação como prática da liberdade. 2. ed. São Paulo: Editora Martins Fontes, 2017.

ISNARDIS, A. Pinturas Rupestres Urbanas: uma etnoarqueologia das pichações em Belo Horizonte. Revista de Arqueologia, Pelotas, v. 10, p. 143-61, 1997.

LEAO, F. M.; SIMÕES, F. L. R.; BARBOSA, A. S.; MACHADO, L. M. Caracterização arqueológica e análise preliminar do Sítio Serra do Mimo (Barreiras, Bahia). In: VII 
Reunião da Associação Brasileira de Arte Rupestre, 2018, Diamantina. Anais da VII Reunião da Associação Brasileira de Arte Rupestre. Diamantina, 2018. V. 1, p. 1-1.

SANTOS JÚNIOR, V. dos. Havia cúpules no caminho: algumas considerações sobre as marcas cupulares nas gravuras rupestres do estado do Rio Grande do Norte e da Paraíba (Ingá). Tarairiú, Campina Grande, Ano III, v.1, n. 5, p. 8-39, set./out. 2012.

SILVA NETO, J. de A. e. Registros rupestres no município de Barreiras, Bahia: o Sítio Arqueológico Serra do Mimo. Monografia (Bacharelado Interdisciplinar em Humanidades) - UFOB, Barreiras, 2017.

TAGUIEFF, Pierre-André. O racismo. Lisboa: Instituto Piaget, 2002.

VAZ, L. J. M. Memória da Pedra Talhada: arte rupestre em Niquelândia GO. Dissertação (Mestrado em Cultura Visual) - FAV/UFG, Goiânia, 2005.

Rafael Petry Trapp: Doutor em História pela UFF, Mestre em História pela PUCRS, com Licenciatura em História pela UNISC. Entre 2016 e 2017 realizou Doutorado Sanduíche na Universidade Columbia (Nova York). Possui interesse nas interfaces entre História e Educação das Relações Étnico-Raciais. É professor substituto da UNEB-IX e colaborador do Mestrado em Ensino e Relações Étnico-raciais da UFSB (CJA-Itabuna).

Orcid: https://orcid.org/0000-0002-7475-2278

E-mail: rafaelpetrytrapp@smail.com

Poliana Silva dos Santos: Graduanda em Pedagogia na Universidade do Estado da Bahia (UNEB), Barreiras, Bahia.

Orcid: https://orcid.org/0000-0002-8689-7298

E-mail: polianasamtos611@gmail.com

Este periódico utiliza a licença Creative Commons Attribution 3.0, para periódicos de acesso aberto (Open Archives Initiative - OAI). 